\title{
Analysis of heating time and of temperature distributions for cylindrical geometry with the use of solution to the inverse problem
}

\author{
Magda Joachimiak ${ }^{1 *}$, and Damian Joachimiak ${ }^{1}$ \\ ${ }^{1}$ Institute of Thermal Engineering, Poznan University of Technology, 60-965 Poznan, Poland
}

\begin{abstract}
Changes in heating time of a cylinder in the furnace for thermal and thermochemical treatments depending on the given heating rate is analysed in this paper. Temperature distributions from the axis to the boundary of the cylinder were determined based on solving non-stationary and non-linear inverse problem for the heat equation. Differences between the temperature on the boundary and along the cylinder axis for processes with the given heating rates from 5 to $10^{\circ} \mathrm{C} / \mathrm{min}$ were calculated. Twofold increase in the heating rate allowed the heating time to be reduced significantly. Increase in the heating rate had no impact on the difference between the temperature on the boundary and on the axis of the cylinder and on the quantity of energy being consumed by heating elements.
\end{abstract}

\section{Introduction}

Monitoring of temperature of the edges of elements heated during processes of thermal and thermochemical treatment is very important due to material structures forming on the surface of the element being treated thermally [1-3]. Knowledge about the surface temperature allows the atmosphere in the furnace to be adjusted more precisely, which involves diffusion of relevant chemicals to heat treated steel and formation of a surface having desired properties [1]. Inverse problems are used to solve many engineering problems [4-9]. Temperature of the heated element can be determined by solving the inverse problem for the heat equation [2,10-14]. Cost of heat treatment processes and time required to conduct such processes are also important. Heating of elements in the furnace for heat treatment demands proper selection of the heating rate. It is particularly important in case of massive elements. An increase in the heating rate results in the reduction in time of treatment what is economically advantageous. However, too fast heating can result in thermal overtension and in a damage of elements under treatment. In this paper we analysed the process of the cylinder heating in the furnace for thermal and thermochemical treatments with horizontal load of the charge (fig. 1), operating in the discontinuous mode. The furnace is cylindrical (fig. 1). The gas flow in the furnace is forced by a fan. The gas flows through the annular channel [15] and then makes reversal at the furnace door. It flows in the furnace chamber as in a reversing chamber [16] (Fig. 1). Distributions of temperature in the cylinder for various heating rates were determined in this paper applying the solution to the inverse problem.



Fig. 1. Furnace for heat treatment.

\footnotetext{
*Corresponding author: magda.joachimiak@put.poznan.pl
} 


\section{Calculation model}

\subsection{Direct problem}

Non-stationary heat equation of the following form was solved

$$
\rho c(T) \frac{\partial T}{\partial t}=\operatorname{div}(\lambda(T) \nabla T)
$$

with the initial condition

$$
T(r, t=0)=T_{0}=0
$$

and the boundary condition

$$
T(r=R, t)=f(t)
$$

Dependence of the specific heat and the heat conduction coefficient on temperature was taken into account. To eliminate non-linearity, the Kirchhoff's substitution was used [17]

$$
\vartheta=\frac{1}{\lambda_{0}} \int_{T_{0}}^{T} \lambda(u) d u=\frac{1}{\lambda_{0}} \int_{0}^{T} \lambda(u) d u
$$

The assumed form of the solution for non-dimensional temperature is the linear combination of the Chebyshev polynomials [18]

$$
\vartheta=\sum_{k=0}^{N} \alpha_{k} W_{k}(\xi) \text { for } \xi \in\langle-1,1\rangle
$$

The solution to the direct problem was reduced to the solution to the matrix equation of the following form

$$
\boldsymbol{\alpha}=\mathbf{A}^{-1} \mathbf{b}
$$

where elements of the vector $\boldsymbol{\alpha}$ are the sought coefficients of the linear combination of the Chebyshev polynomials (form of the solution, equation (5)), whereas the last element of the vector $\mathbf{b}$ is the value of temperature on the boundary in the time unit under consideration $\left(b_{N}=f\left(t_{i}\right)\right)$.

\subsection{Inverse problem}

Unknown boundary condition $f(t)$ was sought based on the known initial condition and on temperature measurement made inside the cylinder at $\mathrm{L}$ points in the plane A (fig. 1). To do so, the functional of the following form, in which squares of differences between the measured and the calculated values for measuring points had been summed, was minimized

$$
I(f)=\sum_{l=1}^{L}\left(T_{c}\left(r_{l}^{*}, f\right)-T_{m}\left(r_{l}^{*}\right)\right)^{2}
$$

Functional (7) has its minimum when the following equation is satisfied

$$
\frac{d I}{d f}=0
$$

Based on equation (8), unknown value of temperature on the boundary of the cylinder was determined. Calculation model is described in detail in reference papers $[2,19]$.

\section{Results of calculations}

Experimental test included heating the cylinder up to the temperature of $550{ }^{\circ} \mathrm{C}$ in neutral atmosphere (nitrogen). Heating rates from 5 to $10{ }^{\circ} \mathrm{C} / \mathrm{min}$ were analysed (table 1). Temperature of gas in the furnace and temperature of the cylinder boundary for the heating processes under consideration were presented in figure 2. In furnaces of such type as the one used for our experiments the most often applied heating rate in industrial conditions is the rate of $5^{\circ} \mathrm{C} / \mathrm{min}$.

Table 1. Heating process parameters

\begin{tabular}{|c|c|}
\hline Process & $\begin{array}{c}\text { Heating rate } \\
{[\mathbf{d C} / \mathbf{m i n}]}\end{array}$ \\
\hline $\mathrm{p} 1$ & 5 \\
\hline $\mathrm{p} 2$ & 6 \\
\hline $\mathrm{p} 3$ & 8 \\
\hline $\mathrm{p} 4$ & 10 \\
\hline
\end{tabular}
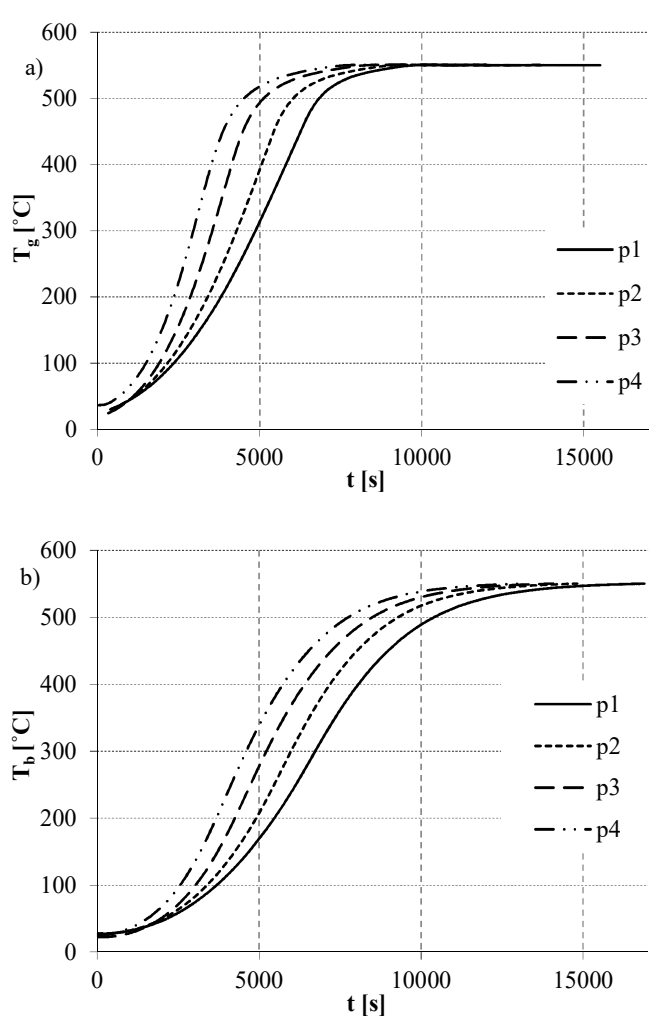

Fig. 2. Gas temperature (a) and temperature of the cylinder boundary (b) for heating processes p1-p4 [2].

Differences between temperature on the boundary and in the axis of the cylinder for processes p1-p4 were calculated (fig. 3). Maximal differences of temperatures ranged from 5.38 to $6.47^{\circ} \mathrm{C}$ (table 2). The change of the heating rate from 5 to $10^{\circ} \mathrm{C} / \mathrm{min}$ resulted in the increase of the difference between the temperature on the boundary and in the axis of the cylinder by $1.09{ }^{\circ} \mathrm{C}$ (table 
2). Distributions of temperature in the cylinder for maximal differences between temperature on the boundary and in the axis of the cylinder are shown in figure 4.

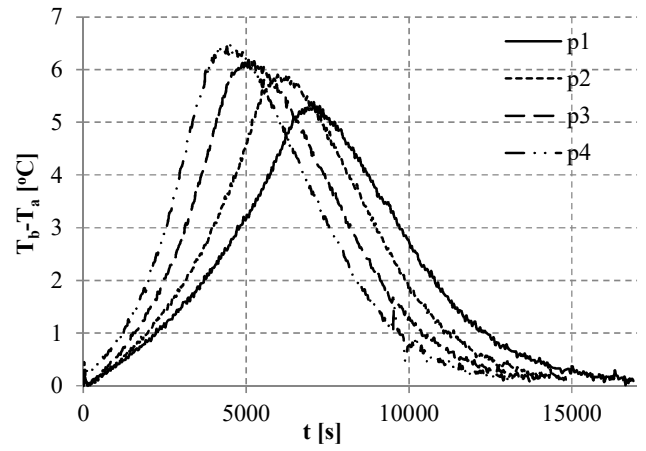

Fig. 3. Temperature difference between the boundary and the axis of the cylinder for heating processes $\mathrm{p} 1-\mathrm{p} 4$.

Table 2. Maximum difference between temperature of the boundary and of the axis of the cylinder for processes with the heating rate ranging from 5 to $10{ }^{\circ} \mathrm{C} / \mathrm{min}$

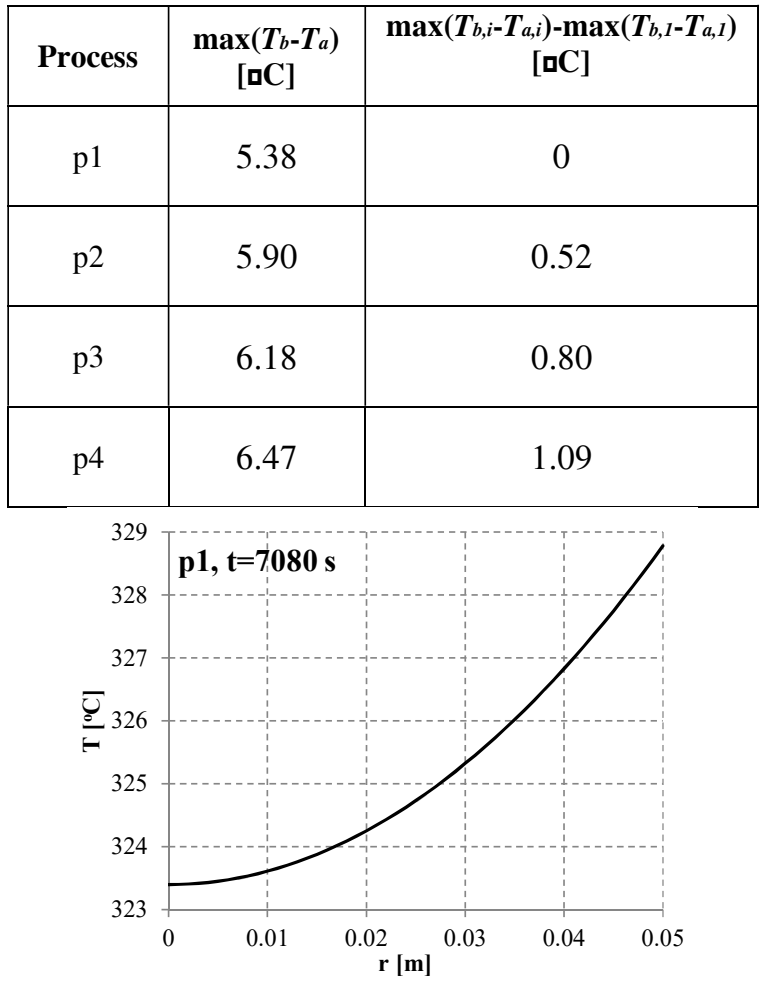

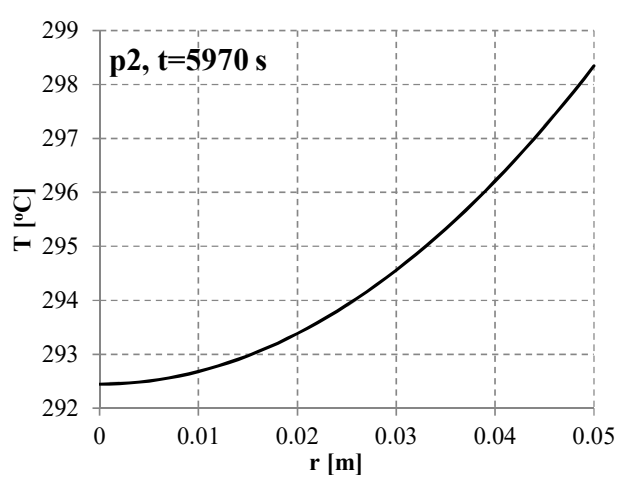

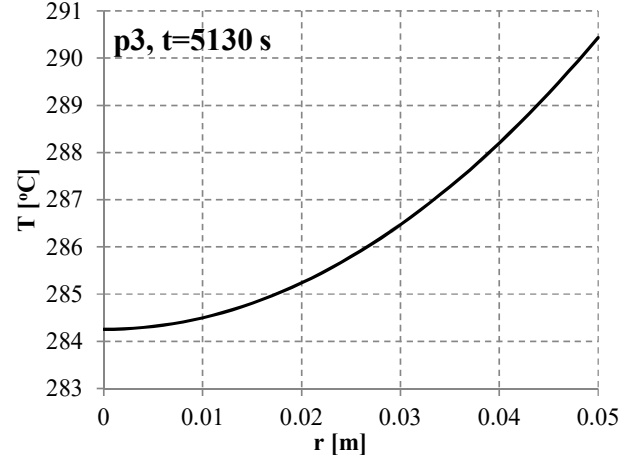

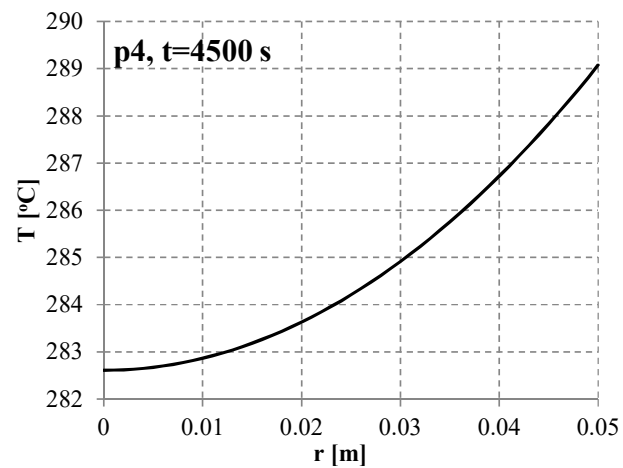

Fig. 4. Distribution of temperature in the cylinder for times of maximal temperature difference between its boundary and axis for processes $\mathrm{p} 1-\mathrm{p} 4$.

Increase in the heating rate reduced the heating time, amounting to $34.5 ; 47$ and 61 minutes, respectively (table 3). The change in the heating rate resulted in changes in energy consumption relative to the process p1, amounting from 3.901 to $12.512 \mathrm{MJ}$ (table 4).

Table 3. Time of the cylinder heating for processes of heating rate from 5 to $10^{\circ} \mathrm{C} / \mathrm{min}$

\begin{tabular}{|c|c|c|}
\hline Process & $\begin{array}{c}\text { Heating } \\
\text { time [s] }\end{array}$ & $\begin{array}{c}\text { Difference between } \\
\text { heating time relative to } \\
\text { process p1 [s] }\end{array}$ \\
\hline $\mathrm{p} 1$ & 16890 & $0(0 \mathrm{~min})$ \\
\hline $\mathrm{p} 2$ & 14820 & $-2070(34.5 \mathrm{~min})$ \\
\hline $\mathrm{p} 3$ & 14070 & $-2820(47 \mathrm{~min})$ \\
\hline $\mathrm{p} 4$ & 13230 & $-3660(61 \mathrm{~min})$ \\
\hline
\end{tabular}

Table 4. Energy consumed by heating elements for processes of heating rate from 5 to $10 \mathrm{dC} / \mathrm{min}$

\begin{tabular}{|c|c|c|}
\hline Process & $\begin{array}{c}\text { Energy } \\
\text { [MJ] }\end{array}$ & $\begin{array}{c}\text { Difference of the } \\
\text { consumed energy relative } \\
\text { to process p1 [MJ] }\end{array}$ \\
\hline $\mathrm{p} 1$ & 207.559 & 0 \\
\hline $\mathrm{p} 2$ & 203.414 & -4.145 \\
\hline $\mathrm{p} 3$ & 195.047 & -12.512 \\
\hline
\end{tabular}




\begin{tabular}{|l|l|l|}
\hline $\mathrm{p} 4$ & 211.46 & 3.901 \\
\hline
\end{tabular}

\section{Conclusion}

Optimization of processes of thermal and thermochemical treatment involves reduction in heating time and in the energy consumption while obtaining elements of the desired surface properties. Of crucial importance is heating of any element with such heating rate that the admissible thermal stresses are not exceeded. In this paper temperature differences between the cylinder boundary and its axis as well as the heating time for the given heating rates of $5,6,8$ and $10^{\circ} \mathrm{C} / \mathrm{min}$ were analysed. Increase in the heating rate from 5 to 10 ${ }^{\circ} \mathrm{C}$ allowed for significant reduction in time of heating amounting to $61 \mathrm{~min}$. It caused a slight increase in the difference of temperature between the cylinder boundary and its axis amounting to $1.09{ }^{\circ} \mathrm{C}$. Changes in the heating rate did not influenced significantly on the energy consumption by heated elements. Optimization of the processes of thermal and thermochemical treatment is a complex problem. This paper is the first step towards the optimization problems solved with the use of the solution to inverse problem for the heat equation.

\section{Nomenclature}

c - specific heat, $\mathrm{J} / \mathrm{kgK}$

div - divergence

$f \quad$ - temperature on the boundary of the cylinder, ${ }^{\circ} \mathrm{C}$

max - maximal value

$r \quad$ - radius, $m$

$R \quad$ - maximal radius, $\mathrm{m}$

$t \quad-$ time, s

$T \quad$ - temperature, ${ }^{\circ} \mathrm{C}$

$W_{i} \quad$ - Chebyshev polynomial of the first kind of i-th degree

$\nabla \quad$ - gradient

$\vartheta \quad$ - temperature in non-dimensional coordinates

$\lambda-$ thermal conductivity, $\mathrm{W} / \mathrm{mK}$

$\xi \quad$ - radius in non-dimensional coordinates

$\rho \quad-$ density, $\mathrm{kg} / \mathrm{m}^{3}$

Superscript:

* - measuring point

Subscript:

$0 \quad$ - initial time, for $t=0$

a - axis

$c$ - calculated value

$b$ - boundary

g - gas

$m$ - measured value

\section{References}

1. L. Małdziński, Kinetic and Technological Aspects of Nitrided Layer Production on Iron and Steel in Gas Nitriding Processes (Wydawnictwo Politechniki Poznańskiej, Poznań, 2002)

2. M. Joachimiak, D. Joachimiak, M. Ciałkowski, L. Małdziński, P. Okoniewicz, and K. Ostrowska, Int. J. Therm. Sci. 145, 105985 (2019)

3. M. Joachimiak, Energies 14, 2903 (2021)

4. Ł. Brodzik, and A. Frąckowiak, Int. J. Numer. Methods Heat Fluid Flow 30, 2989, (2020)

5. D. Joachimiak and A. Frąckowiak, Energies 13, 5794 (2020)

6. D. Joachimmiak and P. Krzyslak, J. Appl. Fluid Mech. 12, 921 (2019)

7. M. Joachimiak, Int. J. Numer. Methods Heat Fluid Flow 30, 4475 (2020)

8. M. Joachimiak, M. Ciałkowski, and Bartoszewicz J., Arch. Thermodyn. 35, 37 (2014)

9. W. Judt, Energies 13, 6141 (2020)

10. A. Frąckowiak, J. V. Wolfersdorf, and M. Ciałkowski, Int. J. Therm. Sci. 136, 370, (2019)

11. K. Grysa, A. Maciąg, and A. Pawińska, Int. J. Heat Mass Transf. 55, 7336 (2012)

12. M. Joachimiak, and M. Ciałkowski, Arch. Thermodyn. 39, 25 (2018)

13. M. Joachimiak, M. Ciałkowski, and A. Frąckowiak, Arch. Thermodyn. 37, 73 (2016)

14. M. Joachimiak, M. Ciałkowski, and A. Frąckowiak, Int. J. Numer. Methods Heat Fluid Flow 30, 1441 (2020)

15. D. Joachimiak, and P. Krzyślak, Arch. Thermodyn. 37, 95, (2016)

16. R. Kłosowiak, J. Bartoszewicz, and R. Urbaniak, Therm. Sci. 23, 1357 (2019)

17. S. Gdula, Heat Conduction (PWN, Warsaw, 1984)

18. S. Paszkowski, Numerical application of multinomials and Chebyshev series (PWN, Warsaw, 1975) 